\title{
NIR spectroscopy based method for charactisation of biological tissue
}

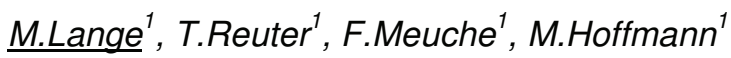 \\ ${ }^{1} \mathrm{fzmb} \mathrm{GmbH}-$ Research Centre for Medical Technology and Biotechnology, \\ Geranienweg 7, 99947 Bad Langensalza, Germany, \\ mlange@fzmb.de
}

\begin{abstract}
We present a Near Infrared Spectroscopy (NIRS) based method for characterisation of biological tissue under mechanical load. In this study we measured NIR spectra of equine cartilage bone samples with simultaneous application of mechanical load. Our goal is to gain more information about the functional behaviour of cartilage tissue to support cartilage therapy.
\end{abstract}

Key words: NIRS, Near Infrared Spectroscopy, characterisation of biological tissue, equine cartilage, simultaneous application of mechanical load, elastic modulus, indentation, relaxation

\section{Introduction}

Near Infrared Spectroscopy (NIRS) is a fast and non-destructive method to characterise tissue [1]. Knee joints sustain body weight, which means the surface of joint cartilage has load sustaining areas. Arthrosis in knee joints is an important issue reducing patients' quality of life. Biomechanical properties are important for tissue that becomes stressed, especially joint cartilage. The combination of NIRS optical method and biomechanical stress application presents the opportunity to investigate functional properties.

\section{Methods}

NIR spectroscopy is based on molecular vibrations. In the near infrared wavelength range, light excites overtone and combination vibrations [2]. Our measurement setup combines simultaneous NIRS and biomechanical load application, as shown in Fig. 2. For spectroscopy we used a Zeiss MCS 1.7 (wavelength range $950-1650 \mathrm{~nm}$ ) and a fibre probe (diameter $\mathrm{d}=2 \mathrm{~mm}$ ). For biomechanical load application we used a motorised linear translation stage Thorlabs MTS50 (maximum velocity $\mathrm{v}=3 \mathrm{~mm} / \mathrm{s}$; maximum acceleration $\mathrm{a}=4 \mathrm{~mm} / \mathrm{s}^{2}$ ) and a force sensor ME systeme K3D120 (max. $50 \mathrm{~N}$ ). The experimental setup was synchronised by our measurement software. In this study equine cartilage bone samples (diameter $\mathrm{d}=10 \mathrm{~mm}$, total $\mathrm{n}=12$ ) were taken, via trepan drill, from Facies Patellaris Femoris Medial at three locations ( $n=3$ each) and at Condylus Medialis Femoris $(n=3)$ as shown in Fig. 1. The samples were stored in isotonic saline for approx. 30 minutes before they became stored in a sample holder for measurement covering samples with isotonic saline. Our measurement sequence started with the detection of the surface when the fibre probe was moved onto the sample until a threshold value of $F=0.5 \mathrm{~N}$ was detected to secure full contact between the fibre probe and the surface. One spectrum per sample was recorded. Then the fibre probe was moved $1 \mathrm{~mm}$ backward and each sample had 30 seconds time for relaxation. Then the load application was performed as an indentation $(\Delta s=0.1 \mathrm{~mm}$ with a speed of $\mathrm{v}=0.5 \mathrm{~mm} / \mathrm{s})$ using the fibre probe. Spectra, force and depth of indentation were recorded during indentation and relaxation (total $t=3$ min per sample). The sampling rate of NIR spectra was $9 \mathrm{~Hz}$, while force and indentation were recorded with $31 \mathrm{~Hz}$. The absorbance spectra were calculated using PTFE reflection as reference (1).
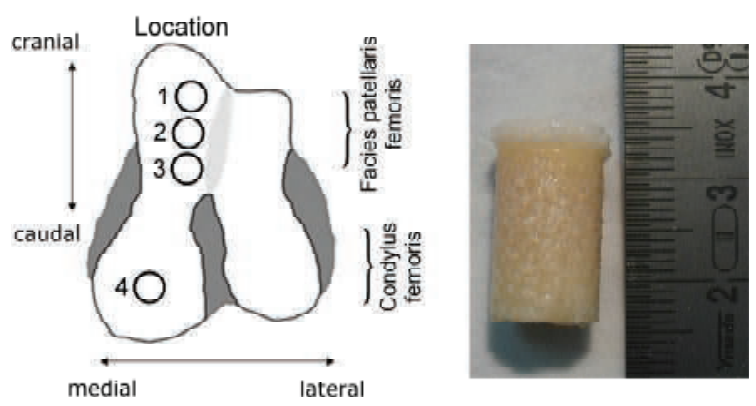

Fig. 1. Sample locations on the equine knee joint (on the left) and one sample (on the right) 
absorbance $=-\log _{10}\left(\frac{\text { sampleSpectrum }- \text { dark }}{\text { referenceSpectrum }- \text { dark }}\right)$

All samples were prepared for histology. The histological sections, coloured with Hematoxylin and Eosin, were used to measure cartilage height.

The biomechanical E-Modulus was calculated assuming that it is a linear stress/strain model disregarding friction between indenter and cartilage. Because of the fast indentation and incompressibility of the cartilage, the Poisson's ratio is defined as $v=0.5$. At strain of $5 \%$ the maximum force and the indentation depth were used in (2)

$$
E=\frac{P\left(1-v^{2}\right)}{2 a \omega \delta\left(v, \frac{a}{h}\right)}
$$

with $\mathrm{P}$ - Force /N, v - Poisson's ratio, a - radius of indentor $/ \mathrm{mm}, \omega$-indentation depth $/ \mathrm{mm}$, h sample height $/ \mathrm{mm}, \delta$ - Factor depending on geometry and material taken from [3][4].

\section{Results}

The histology delivered the cartilage thickness (sample height, table 1), which is $\mathrm{h}=1.25 \pm 0.16 \mathrm{~mm}$ at location $1-3$ and $\mathrm{h}=2.14 \pm 0.33 \mathrm{~mm}$ at location 4 . The full spectra, taken directly after detection of the surface, are shown in Fig. 3. In the detector's wavelength range are several absorbance bands of $1^{\text {st }}, 2^{\text {nd }}$ overtones and combination vibrations. The absorbance features three main absorbance maxima at $\lambda=950 \mathrm{~nm}, 1174 \mathrm{~nm}$ and $1450 \mathrm{~nm}$. To investigate the functional behaviour of tissue we chose the $950 \mathrm{~nm}$ wavelength region for the depiction of the time course during measurement. The qualitative course is equivalent at location 1, 2, and 3 and different at location 4. The decrease of absorbance during indentation and the increase during relaxation is shown in Table 1 and depicted in Fig. 4. There is a different behaviour of the cartilage at location 4 (Condylus Femoris, -0.051 to $-0.087 \mathrm{AU}$ during indentation) compared to location 1-3 (Facies Patellaris Femoris, -0.044 to $-0.066 \mathrm{AU}$ ). To visualise the varying behaviour of equine cartilage taken from miscellaneous locations we show $\Delta \mathrm{A}_{\text {indentation }}$ vs. $\Delta \mathrm{A}_{\text {relaxation }}$ in Fig. 5.

Tab. 1: Change of Absorbance during indentation and relaxation of $n=12$ samples, and sample height (cartilage thickness)

\begin{tabular}{|c|c|c|c|}
\hline sample & $\begin{array}{c}\Delta \mathrm{A}_{\text {indentation }} \\
/ \mathrm{AU}\end{array}$ & $\begin{array}{c}\Delta \mathrm{A}_{\text {relaxation }} \\
/ \mathrm{AU}\end{array}$ & $\begin{array}{c}\text { Sample height } \\
/ \mathrm{mm}\end{array}$ \\
\hline $\mathrm{P}_{1}-1$ & -0.063 & 0.043 & 1.30 \\
\hline $\mathrm{P}_{1}-2$ & -0.066 & 0.054 & 1.34 \\
\hline $\mathrm{P}_{1}-3$ & -0.044 & 0.045 & 1.25 \\
\hline $\mathrm{P}_{2}-1$ & -0.055 & 0.055 & 1.03 \\
\hline $\mathrm{P}_{2}-2$ & -0.057 & 0.063 & 1.09 \\
\hline $\mathrm{P}_{2}-3$ & -0.046 & 0.042 & 1.32 \\
\hline $\mathrm{P}_{3}-1$ & -0.055 & 0.049 & 1.39 \\
\hline $\mathrm{P}_{3}-2$ & -0.050 & 0.056 & 1.06 \\
\hline $\mathrm{P}_{3}-3$ & -0.059 & 0.054 & 1.48 \\
\hline $\mathrm{F}-1$ & -0.087 & 0.023 & 2.47 \\
\hline $\mathrm{F}-2$ & -0.051 & 0.023 & 2.16 \\
\hline $\mathrm{F}-3$ & -0.074 & 0.023 & 1.80 \\
\hline
\end{tabular}

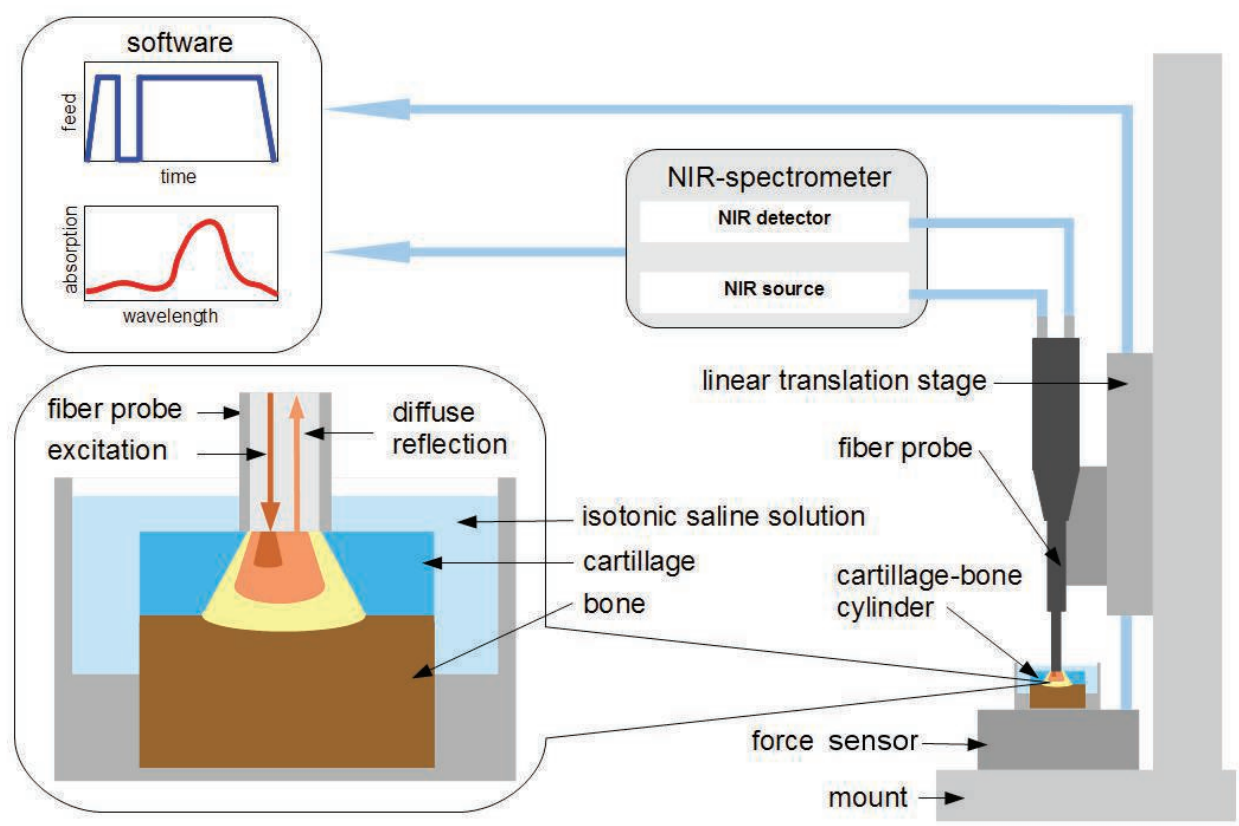

Fig. 2. Experimental setup 


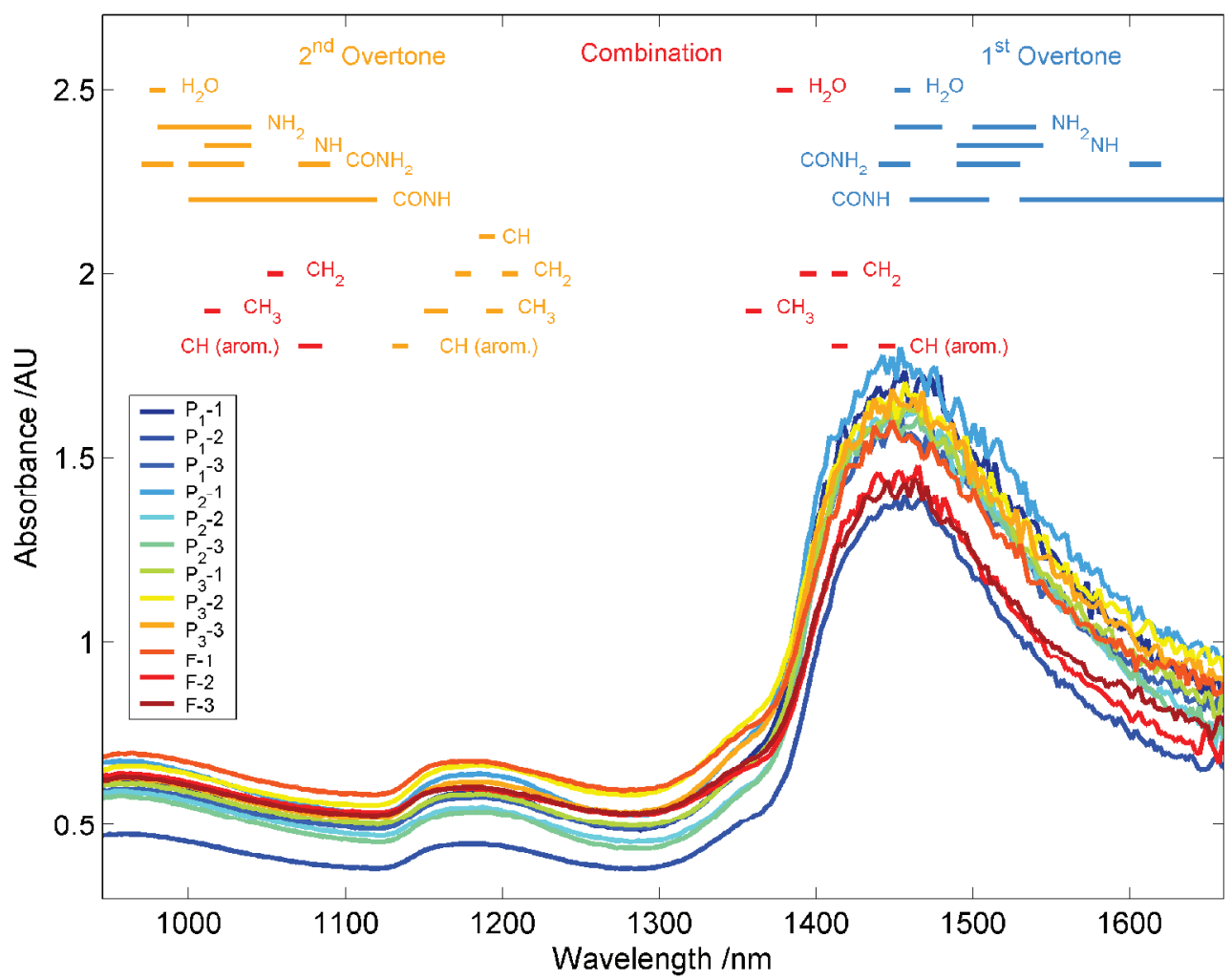

Fig. 3. Calculated absorbance of $n=12$ cartilage samples with $0.5 \mathrm{~N}$ compression load before indentation, and visualisation of absorbance bands [5]
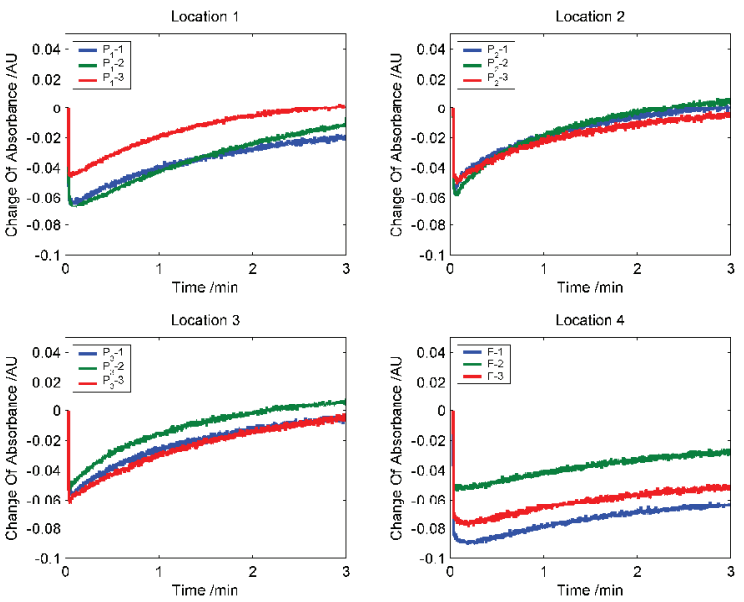

Fig. 4. Change of Absorbance of four locations (Location 1-3: Facies Patellaris Femoris; Location 4: Condylus Femoris; $n=3$ each) during indentation and relaxation at the wavelength of $\lambda=950 \mathrm{~nm}$

There are two groups: all samples taken from Facies Patellaris Femoris Medial (blue) and the samples taken from Condylus Medialis Femoris (red).

The force-indentation-diagram is shown in Fig. 6. During indentation the applied force, approximately, increases linearly. After indentation the tissue relaxes and the applied force decreases, this is reverse to absorbance. During indentation the absorbance decreases, while the absorbance increases during relaxation.

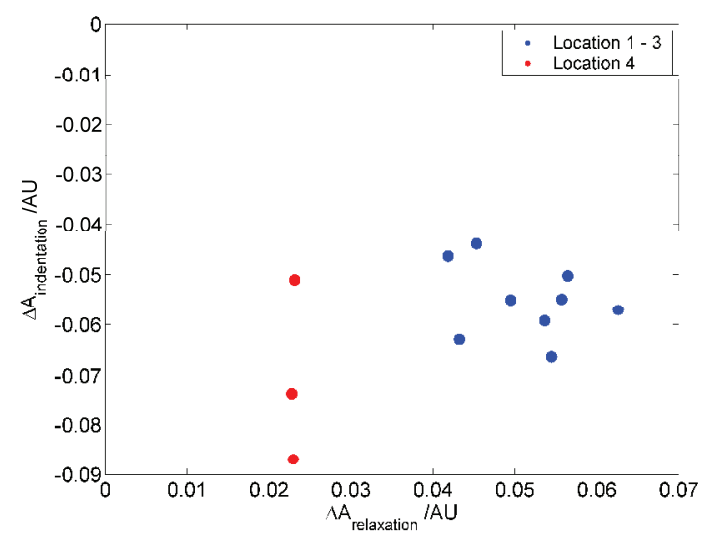

Fig. 5. Scatterplot of $\Delta A_{\text {indentation }}$ vs. $\Delta A_{\text {relaxation }}$ with colour coded Location 4 (red) and Location 1-3 (blue)

We have an indentation offset caused by our detection of the surface with a force of $F=0.5 \mathrm{~N}$ as shown in table 2. Considering this offset, we calculated the relative indentation depth. At $5 \%$ strain (linear approximation) the E-Modulus is $\mathrm{E}=1.75 \pm 0.29 \mathrm{MPa}$ (location 1-3) and $\mathrm{E}=1.11 \pm 0.07 \mathrm{MPa}$ (location 4). The scatterplot of $\mathrm{E}$-Modulus vs. $\Delta \mathrm{A}_{\text {relaxation }}$ is shown in Fig. 7. It's obvious, that there are two clusters. 

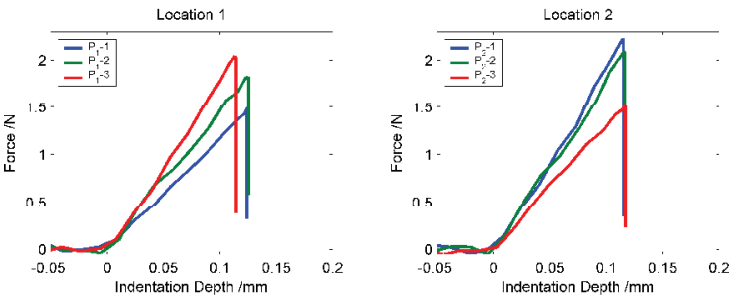

Location 3
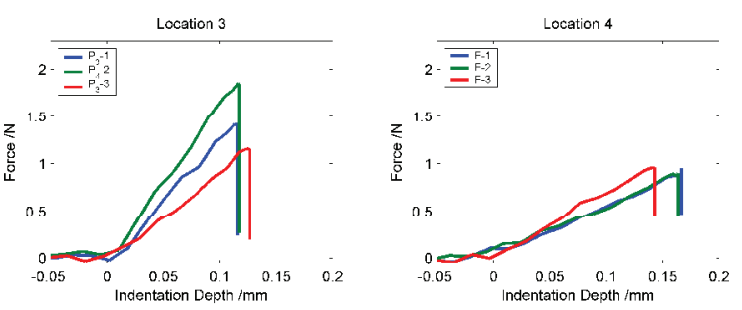

Fig. 6. Force-Indentation-diagrams (with offset correction of indentation depth, linear approximation; Location 1-3: Facies Patellaris Femoris; Location 4: Condylus Femoris)

Tab. 2: Results of the biomechanical load application

\begin{tabular}{|c|c|c|c|c|}
\hline sample & $\begin{array}{c}\text { maximum } \\
\text { force } \\
/ \mathrm{N}\end{array}$ & $\begin{array}{c}\text { indentation } \\
\text { offset } \\
/ \mathrm{mm}\end{array}$ & $\begin{array}{c}\text { relative } \\
\text { indentation } \\
\text { depth } / \%\end{array}$ & $\begin{array}{c}\text { E-Modulus } \\
5 \% \text { strain } \\
/ \mathrm{MPa}\end{array}$ \\
\hline $\mathrm{P}_{1}-1$ & 1.49 & 0.020 & 9.23 & 1.46 \\
\hline $\mathrm{P}_{1}-2$ & 1.83 & 0.023 & 9.17 & 2.08 \\
\hline $\mathrm{P}_{1}-3$ & 2.05 & 0.015 & 9.20 & 2.16 \\
\hline $\mathrm{P}_{2-1}$ & 2.23 & 0.012 & 10.83 & 1.79 \\
\hline $\mathrm{P}_{2}-2$ & 2.10 & 0.005 & 9.59 & 1.90 \\
\hline $\mathrm{P}_{2}-3$ & 1.54 & 0.017 & 8.90 & 1.65 \\
\hline $\mathrm{P}_{3}-1$ & 1.42 & 0.012 & 8.09 & 1.74 \\
\hline $\mathrm{P}_{3}-2$ & 1.86 & 0.012 & 10.60 & 1.72 \\
\hline $\mathrm{P}_{3}-3$ & 1.16 & 0.032 & 8.94 & 1.24 \\
\hline $\mathrm{F}-1$ & 0.95 & 0.063 & 6.62 & 1.16 \\
\hline $\mathrm{F}-2$ & 0.90 & 0.065 & 7.62 & 1.03 \\
\hline $\mathrm{F}-3$ & 0.96 & 0.049 & 8.28 & 1.13 \\
\hline
\end{tabular}

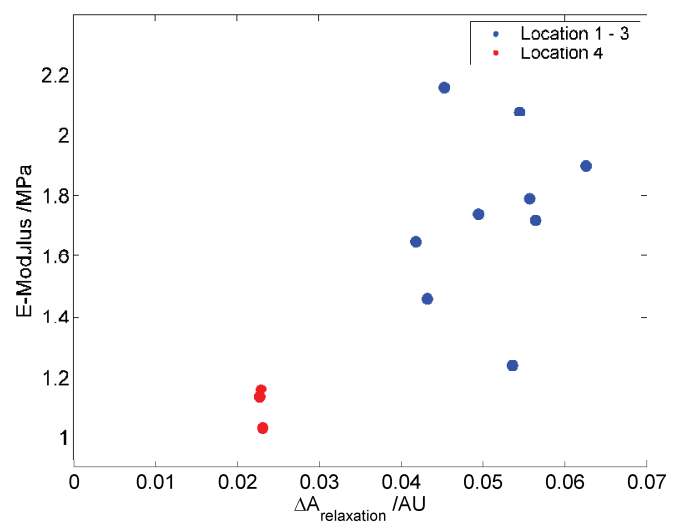

Fig. 7. Scatterplot E-Modulus vs. $\Delta A_{\text {relaxation }}$ of four locations (Location 1-3: Facies patellaris femoris; Location 4: condylus femoris) showing two clusters

\section{Discussion and Conclusion}

In this study we recorded spectra of cartilage during varying load situations. For material testing the percentage indentation depth (i.e. $5 \%$ or $10 \%$ ) is generally preferable to constant indentation. Since thickness measurement by needle indentation and histology is destructive, cartilage thickness was unknown during our measurements. Therefore a NIRS calibration to predict sample thickness before the mechanical measurement is required to improve the accuracy and reliability of our biomechanical measurement.

Our goal for further work is to expand the material models by usage of biphasic and triphasic theory [6]. So we can generate calibrations with biomechanical parameters like permeability, aggregate modulus etc. Additionally, we will use an advanced experimental setup with extended wavelength range $(900-2200$ $\mathrm{nm}$ ) and a material testing machine (Zwick Roell) for creep and relaxation tests.

\section{Acknowledgement}

Supported by:

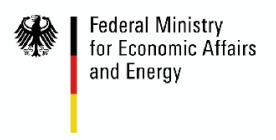

on the basis of a decision by the German Bundestag
This study was funded by the German Federal Ministry for Economic Affairs and Energy (VF090058) on the basis of a decision by the German Bundestag.

\section{References}

[1] G. Spahn, H.M. Klinger, M. Baums, M. Hoffmann, H.K. Plettenberg, A. Kroker, G.O. Hofmann: Near-Infrared Spectroscopy for Arthroscopic Evaluation of Cartilage Lesions - Results of a Blinded, Prospective, Interobserver Study, Am J Sports Med. PreView, 16.09.2010, DOI $10.1177 / 0363546510376744$

[2] J. Workman Jr, L.Weyer: Practical Guide to Interpretive Near-Infrared Spectroscopy, CRC Press 2008, ISBN: 978-1-57444-784-2

[3] M. Zhang, Y.P. Zheng YP, A.F.T. Mak: Estimating the effecive Young's modulus of soft tissues from indentation tests - nonlinear finite element analysis of friction And large deformation, Med. Eng. Phys., Vol. 19, No. 6, pp. 512-517, 1997.

[4] W.C. Hayes, L.M. Keer, G. Herrmann, L.F. Mockros: A Mathematical analysis for indentation of articular cartilage, J Biomechanics, 1972, Vol. 5, pp. 541-551.

[5] Understanding Spectra, Improving Spectra: Near Infrared Band Assignment Table, Bruker Optics

[6] W.M. Lai, J.S. Hou, V.C. Mow: A triphasic Theory for the Swelling and Deformation Behaviors of Articular Cartilage, J Biomechanical Eng, Vol. 113, pp. 245-258, 1991 